\title{
HEART FAILURE AND FIRST DOSE HYPOTENSION AFTER ANGIOTENSIN CONVERTING ENZYME INHIBITORS
}

\author{
Jiří Vítovec ${ }^{\mathrm{a}}$, Jindřich Špinar \\ ${ }^{a} I^{\text {st }}$ Department of Internal Medicine - Cardioangiology, Faculty Hospital, St. Anne’s, Pekarska 53, 65691 Brno \\ ${ }^{b}$ Department of Internal Medicine-Cardiology; Faculty Hospital Brno-Bohunice, Jihlavska 20, 62500 Brno, Czech \\ Republic \\ e-mail:jiri.vitovec@fnusa.cz
}

Received: September 15, 2004; Accepted: September 30, 2004

Key words: ACE inhibitors/Heart Failure/Myocardial Infarction/First-Dose Hypotension

The first-dose induced decrease in blood pressure in some patients following the administration of ACE inhibitors is a fact causing some concern among clinicians prescribing these drugs. However, an overview of clinical trials and the authors' own experience clearly point to the possibility of reducing the incidence and/or severity of first-dose hypotension. Apart from appropriate clinical measures to be taken, the choice of the ACE inhibitor seems to be of crucial importance as some (fosinopril, perindopril) produce less hypotension than others. Thus, with due circumspection, $\mathrm{ACE}$ inhibitors can safely retain their position as the cornerstone of the treatment of chronic heart failure.

First-dose hypotension has been recognized as a potential limiting factor in the use of ACE inhibitors in the treatment of chronic heart failure (CHF) and after acute myocardial infarction (AMI). Concerns regarding firstdose hypotension may increase the risk of renal, myocardial, or cerebral hypoperfusion that may result. The incidence of first-dose hypotension after ACE inhibitors reported in large clinical trials is small, varying from $0.7 \%$ in the SAVE trial to $13.3 \%$ in the OPTIMAAL trial ${ }^{1,2}$. This variation reflects differences in study design, in patient selection, in the definition of first-dose hypotension, and in drug selection. The major reason for the low number of these events reported is a very infrequent use of ambulatory blood pressure monitoring, and thus the incidence of less than $10 \%$ reflects only symptomatic or casually measured hypotension. A number of smaller trials have reported a much higher incidence of first-dose hypotension, affecting as many as one third of the patients.

\section{SYMPTOMS OF FIRST-DOSE HYPOTENSION}

The most frequently reported symptoms of drug-induced hypotension are those related to cerebral hypoperfusion. These include light headiness, dizziness, headache, general weakness and visual disturbances ${ }^{3}$.

In elderly patients, drug-induced hypotension has also been associated with falling. Several studies conducted in the community and in long-term residential care facilities have found drug-induced hypotension to be the primary cause of falling in both fit and frail elderly patients ${ }^{4-6}$. The clinical consequences of first-dose hypotension assume particular relevance in this patient population because the compensatory circulatory response to hypotensive stimuli, pre-existing vascular disease or both declines with age ${ }^{7,34}$.

With more severe first-dose hypotension, the subsequent drop in cerebral blood flow can lead to a sudden brief loss of consciousness (syncope), often accompanied by bradycardia ${ }^{8}$. This may be especially dangerous in patients with heart failure. The incidence of syncope following initiation of an ACE inhibitor appears to have decreased dramatically over the last decade to between 0.5 and $2.2 \%$, although this may reflect changes in reporting practices $^{9,10}$. Many clinicians continue to monitor closely the response to the first dose of an ACE inhibitor in patients with grade 3 or 4 heart failure (NYHA criteria) and in those who present low BP.

\section{CLINICAL CONSEQUENCES}

In most patients the fall in BP is relatively mild and transient, and the majority of patients remain asymptomatic. However, in susceptible individuals, particularly the elderly and those with heart failure, first-dose hypotension can be profound and the clinical consequences can be more dangerous. Severe hypotension is not infrequently associated with cardiac, renal and neurological complications, and occasionally death ${ }^{9}$.

Mets and colleagues reported that administration of a first dose of captopril $(6.25 \mathrm{mg})$ in 97 elderly patients (mean age 84 years) with chronic heart failure resulted in systolic blood pressure (BP) being reduced by $15 \%$ (generally within 60 minutes) in $54 \%$ of recipients ${ }^{11}$. Furthermore, the fall in systolic BP exceeded $30 \%$ in $5 \%$ of patients. Such profound reductions in BP may precipitate end-organ ischaemic damage in patients with preexisting 
vascular disease, and may lead to elderly patients falling and sustaining injuries ${ }^{12}$. Discontinuation of the ACE inhibitor, and hence the loss of the long-term benefit from this therapy, is perhaps the most important clinical consequence of first-dose hypotension.

\section{HEART FAILURE}

ACE inhibitors now represent one of the cornerstones of the treatment of chronic heart failure ${ }^{13}$. A large number of well-controlled studies have demonstrated less morbidity and mortality after initiation of ACE inhibitor therapy in patients with $\mathrm{CHF}^{14-17}$. Furthermore, in patients with asymptomatic impairment of left ventricular function following myocardial infarction, ACE inhibitors improve both morbidity and mortality indices ${ }^{16,18}$.

Nevertheless, despite their undoubted benefits, ACE inhibitors may be associated with troublesome adverse reactions, some of which may necessitate interruption of therapy. Systemic hypotension, usually occurring after the initial dose, is the one of the most common adverse events occurring with ACE inhibitor therapy in patients with chronic heart failure ${ }^{10}$. This decline in blood pressure (BP) varies in magnitude and is well tolerated by most patients. However, systemic hypotension occurring after initiation of ACE inhibitor therapy is often not diagnosed and there is the potential for serious sequellae in some patients $^{19,20}$

In the majority of clinical trials of ACE inhibitors in patients with heart failure, the reported incidence of symptomatic first-dose hypotension ranged from 2 to $33 \% 8,14,21-24$. The randomized comparative trial by Packer et al. confirmed the results of earlier non-comparative studies that demonstrated an increased frequency of early severe symptomatic hypotension, associated with renal failure and myocardial ischemia, in heart failure patients ${ }^{24}$. Subsequent studies, including 2 large, randomized controlled trials, also demonstrated this first-dose BP response. Hasford et al. reported an incidence of $5.2 \%$ in 599 patients, and in the same year the SOLVD investigators reported a $2.2 \%$ incidence of first-dose hypotension in 7402 patients. The results of these 2 studies are particularly relevant since they reflect the current clinical practice of commencing therapy with dosages that are much lower than those that were used when captopril and enalapril were first introduced ${ }^{14,23}$.

The first-dose hypotensive effects of ACE inhibitor therapy in heart failure patients have been specifically evaluated in several smaller controlled clinical trials. In a report of 2 non-blind, randomized, crossover studies conducted simultaneously, single $10 \mathrm{mg}$ doses of lisinopril $(n=12)$ and enalapril $(n=12)$ produced mean maximum reductions in arterial BP versus baseline that were comparable (19 and $25 \mathrm{mmHg}$, respectively) and also occurred at the same time (3.5 hours) after administration ${ }^{25}$. Similarly, in 2 randomized double-blind studies involving a total of 24 patients, there were no significant differences between enalapril and lisinopril ${ }^{26}$ or between enalapril and atenolol ${ }^{27}$ in the magnitude and time of onset of hypotension after administration. A first-dose hypotensive effect with quinapril has also been demonstrated ${ }^{28}$. Single-dose quinapril $2.5 \mathrm{mg}$ elicited a significant $(\mathrm{p}<0.05)$ fall in mean arterial BP compared with placebo 3 to 10 hours after administration in a randomized double-blind trial involving 24 elderly patients (aged 54 to 88 years) with chronic heart failure. The maximum decrease $(12 \mathrm{mmHg})$ occurred 5 hours post dose. This sustained BP response was associated with prolonged inhibition of circulating ACE. Our study compared perindopril $2 \mathrm{mg}$ and enalapril $2,5 \mathrm{mg}^{29}$. Patients $(\mathrm{N}=298)$ with chronic heart failure due to ischaemic heart disease or dilated cardiomyopathy, NYHA II-IV, ejection fraction $<40 \%$, age > 18 years, naive to ACE inhibitors or ATI-receptor blocker, were randomized to receive a single dose of $2.5 \mathrm{mg}$ enalapril or $2.0 \mathrm{mg}$ perindopril. Ambulatory blood pressure monitoring started 2 hours before the study medication was given. The maximum drop in blood pressure appeared approximately 4 hours after dose administration in both groups, and was more pronounced in the enalapril group. Patients in the enalapril group had a significantly higher incidence of asymptomatic hypotension. No symptomatic hypotension requiring a change in medication or a prolongation of hospitalization was observed.

We have compared high dose of spirapril - $6 \mathrm{mg}$ after the first administration and after 2 weeks of treatment in 24 patients with chronic heart failure NYHA II-IV and in 12 healthy volunteers ${ }^{30}$. The decrease was the same on days 1 and 14 and was higher and lasted longer in heart failure patients than in healthy volunteers. We suppose that the hypotensive effect is dependent on the renin-angiotensin system activation.

Eryonucu et al. have compared the safety and tolerability of fosinopril (10 mg) and captopril $(6.25 \mathrm{mg})$, in diuretic treated, salt depleted "high risk" patients. Captopril produced a significant early and brief fall in BP, while the first-dose hypotensive response with fosinopril did not differ significantly from placebo ${ }^{31}$.

In study Navookarasu et al. a Malaysian experience were compared placebo, captopril $6.25 \mathrm{mg}$, enalapril $2.5 \mathrm{mg}$, perindopril $2 \mathrm{mg}$ and lisinopril $2.5 \mathrm{mg}$ and only perindopril, unlike other ACE inhibitors studied, did not produce first dose hypotension ${ }^{32}$.

Similar findings were published by Jansen et al. ${ }^{33}$ or Portuguese Study Group ${ }^{54}$ by comparison captopril with perindopril, which caused less BP reduction.

In Val-HEFT study were reported only $1.3 \%$ hypotension after valsartan compared $0.8 \%$ placebo $^{62}$.

\section{MYOCARDIAL INFARCTION}

Increased clinical experience, including the results of several large intervention trials (AIRE, SAVE, ISIS-4, GISSI-3, TRACE), has established a place for ACE inhibitors as adjunctive therapy in the management of postMI patients ${ }^{1,16,35-37}$. The reported incidence of first-dose hypotension in these studies ranged from 0.7 to $10.5 \%$. 
In the 2 largest trials, the First Chinese Cardiac Study (CCS-1; $\mathrm{n}=6814)$ and ISIS-4 ( $\mathrm{n}=29$ 028), the incidences of first-dose hypotension were 9.4 and $5.3 \%$, respectively. The most common reason for terminating treatment in the CCS-1 study was hypotension (8.4\% of captopril recipients $v s$. $4.9 \%$ of placebo recipients $)^{18}$. In the CONSENSUS II study, which involved 6090 patients, acute administration of ACE inhibitors following MI was associated with a $7 \%$ incidence of first-dose hypotension, compared with $2 \%$ in the placebo group. Moreover, there was a $15 \%$ excess (vs. placebo), of hypotension occurring at any time in the enalapril group - this may have been associated with increased mortality. The investigators hypothesized that the hypotension may have accounted for the lack of any beneficial effect seen in this trial ${ }^{38}$. This disappointing experience with ACE inhibitors following acute $\mathrm{MI}$ has not been reflected in several subsequent studies. For example, the AIRE and GISSI-3 trial, the occurrence of persistent hypotension was not associated with any increase in mortality. In the AIRE study, which involved 2006 patients, the respective incidences of hypotension and syncope were $4.2 \%$ and $2.4 \%$ in patients treated with ramipril, and $2.3 \%$ and $1.7 \%$ in the placebo group. Similarly, the Gruppo Italiano investigators reported persistent hypotension (defined as systolic BP $<90$ $\mathrm{mmHg}$ for $>1$ hour) and renal dysfunction, respectively, in $8.8 \%$ and $2.4 \%$ of patients treated with lisinopril alone, compared with $3.9 \%$ and 1.1 of those given nitrates alone, and $3.6 \%$ and $1.1 \%$ in the placebo group. In this trial, the main reasons for lisinopril withdrawal were hypotension (9.7\% of patients) and renal impairment ( $2 \%)$. Although it was not stated in either trial whether these effects were directly related to the first dose of the ACE inhibitor, there is evidence that the BP response to repeated administrations is directly related to the first-dose response ${ }^{24,39}$.

Weber et al. compared BP response in 205 patients with left ventricular dysfunction after AMI captopril and trandolapril. Short-term treatment with trandolapril tended to be better tolerated than captopril ${ }^{61}$.

We have compared the blood pressure fall after losartan and captopril in 320 patients with acute myocardial ${ }^{40}$. The maximal blood pressure fall appeared about 1 hour after the dose first dose of captopril and 3 and a half hours after the first dose of losartan. Patients in the captopril group had significantly higher incidence of asymptomatic hypotension $(\mathrm{p}<0,001)$. No difference in hypotension requiring a change in medication was observed. Berkin and Ball ${ }^{41}$ commented on these findings. It would be interesting to see the outcome in large patients numbers where agents had been used singly as alternatives and in combination.

Our results have been partly confirmed. A recently published VALIANT trial compared valsartan, captopril and their combination in 14703 patients with acute myocardial infarction, left ventricle dysfunction or signs of heart failure ${ }^{42}$. The highest incidence of clinically significant hypotension was in the combination group, the lowest in the captopril group ( $18.2 \%$ vs. $15.1 \%$ vs. $11.9 \%$ )
Two large clinical trials in patients with ischaemic heart disease and without heart failure - HOPE and EUROPA - showed $<3 \%$ hypotension during a run in the open label period ${ }^{43,44}$.

\section{RISK FACTORS}

It is not surprising that inhibition of the RAS, the primary function of which is volume homeostasis and maintenance of BP, should result in an initial lowering of BP. However, the precise etiology of ACE inhibitor firstdose hypotension remains unclear. Several possible mechanisms have been proposed, including reduced venous return to the heart because of indirect inhibition of sympathetic venous tone through a decrease in angiotensin II levels, and activation of the Bezhold-Jarisch reflex by vagally mediated hypotension and bradycardia ${ }^{45,46,55}$.

Identifying and correcting individual risk factors associated with the development of hypotensive episodes may minimize the risk of first-dose hypotension. Although the pathophysiology of first-dose hypotension remains undefined, several risk factors for its occurrence have been suggested. Primary risk factors are probably hyponatraemia, hypovolemia resulting from diuretic therapy, low baseline systolic BP $(<100 \mathrm{mmHg})$ or baseline diastolic BP, high renin or aldosterone levels, renal impairment and heart failure ${ }^{56-60}$. Certainly, the results of the prerandomisation test-dose phase of the SOLVD trial emphasized the greater propensity for patients with severe CHF (NYHA criteria) or low baseline systolic BP, or both, to develop hypotension after the first dose of enalapril ${ }^{47}$.

There is a greater probability of an acute fall in BP when a patient has high plasma renin and angiotensin II levels prior to administration of an ACE inhibitor. Indeed, the findings of at least one group of investigators implicate pretreatment levels of circulating angiotensin II as a risk factor for first-dose hypotension ${ }^{48}$. Consequently, first-dose hypotension is more often seen in patients with renovascular hypertension or those receiving diuretic therapy.

There may also be a greater tendency for first-dose hypotension to occur in individuals who are hypovolemic or hyponatremic. Acute hypotension has been observed in sodium- and water-depleted patients. Circulatory collapse has been reported in a patient who commenced ACE inhibitor therapy after developing diarrhea that led to severe volume depletion ${ }^{49}$.

ACE inhibitor dosage as well the onset and duration of action of an ACE inhibitor can also be considered as risk factors. After specifically investigating the first-dose hypotensive effects of enalapril, Cleland et al. recommended the use of a much lower initial dose (2.5 vs. $10 \mathrm{mg}$ ) to reduce the duration of ensuing hypotension ${ }^{8}$. This recommendation was subsequently supported by Packer et al., who concluded that the use of a high, fixed dose of a long-acting ACE inhibitor such as enalapril may produce prolonged hypotensive effects, resulting in endorgan acute ischemia ${ }^{24}$. Other investigators have also sug- 
gested an association between the initial dose of an ACE inhibitor and the magnitude of the first-dose hypotensive effect $^{45,49}$. Conversely, McLay et al. have demonstrated that the size of the starting dose of captopril, a short-acting drug, does not significantly affect the magnitude of the fall in $\mathrm{BP}^{39}$. They suggested that captopril can be initiated on an outpatient basis if patients are observed for at least 1 to 5 hours after their first dose. Nevertheless, it now seems to be accepted generally that ACE inhibitor therapy should be initiated at a low dosage and then titrated to the maximum tolerated dosage.

\section{SPECIFIC DIFFERENCES BETWEEN ACE INHIBITORS}

The results of some controlled clinical studies indicate that there are variations in hemodynamic responses to different ACE inhibitors, and that these appear to be associated, at least in part, to differences in ACE binding kinetics.

MacFadyen et al. demonstrated significantly greater mean maximum reductions in BP compared with placebo after single doses of captopril or enalapril, but not perindopril, in a randomized, double-blind study in 48 elderly patients (aged 58-85 years) with chronic heart failure. The mean maximum BP fall after administration of perindopril did not differ significantly from placebo at any time during the study. The maximum decrease in BP with enalapril occurred later than that with captopril ( 5 vs. 1.5 hours), and the acute BP-lowering effects of enalapril also lasted longer (10 vs. 3 hours). Despite not causing a significant reduction in BP, perindopril's inhibition of plasma ACE was comparable to that of elanapril. This observation reflects clinically relevant agent-specific differences in hemodynamic responses ${ }^{46}$.

The finding that perindopril does not elicit a significant first-dose effect was subsequently confirmed in a randomized, double-blind follow-up study which compared single doses of enalapril $2.5 \mathrm{mg}$ and perindopril $2 \mathrm{mg}$ in 48 patients with $\mathrm{CHF}$. Enalapril produced a fall in arterial $\mathrm{BP}$ (mean maximum, $21 \mathrm{mmHg}$ ), whereas the decrease noted with perindopril $(16 \mathrm{mmHg})$ was similar to that with placebo ( $15 \mathrm{mmHg}$ ). The absence of a firstdose hypotensive response after perindopril administration was demonstrated over a 48-hour period. We have found similar results in our study (298 patients). The maximum drop in blood pressure appeared approximately 4 hours after dose administration in both groups, and was more pronounced in the enalapril group. Patients in the enalapril group had a significantly higher incidence of asymptomatic hypotension. No symptomatic hypotension requiring a change in medication or a prolongation of hospitalization was observed ${ }^{29}$.

Mac Fadyen et al. results indicated an earlier, shortlived, first-dose effect of captopril versus enalapril. This has also been demonstrated in a randomized double-blind comparison in 117 patients with heart failure. The mean maximum BP decreases after the first dose occurred significantly ( $\mathrm{p}<0.05$ ) earlier with captopril $6.25 \mathrm{mg}$ (1-2 hours) than with enalapril $2.5 \mathrm{mg}$ ( $4-5$ hours). The maximum reductions after first doses of enalapril versus captorpil, respectively, in mean supine systolic (6.2 vs. $8.3 \mathrm{mmHg}$ ) and diastolic (4.8 vs. $6.4 \mathrm{mmHg}) \mathrm{BP}$ were significantly $(\mathrm{p}<0.001)$ different from baseline values; however, there was no significant difference between the two agents with respect to the magnitude of effect. In addition, the duration of significant ( $p<0.05 v s$. placebo) BP lowering was longer for enalapril (3-7 hours) than for captopril (0.5-3 hours). In 3 previously mentioned studies, lisinopril produced a reduction in mean maximum BP comparable to that of enalapril ${ }^{25,}{ }^{26}$ and quinapril ${ }^{28}$ induced a significant $(\mathrm{p}<0.05)$ reduction in mean BP versus placebo.

The reasons for the differences in hemodynamic response between ACE inhibitors are not known, but ACE-binding kinetics may play a role. Certainly, there are differences between ACE inhibitors in the extent and affinity of binding to ACE that are mainly dependent on the chemical structure and concentration of the ACE inhibitor at the binding site. Greater lipophilicity improves tissue penetration and therefore increases drug availability at the site of action. Hence, drugs with high lipophilicity may facilitate increased inhibition of tissue ACE. In addition, most ACE inhibitors are prodrugs that exist in an esterified form to improve absorption ${ }^{50,51}$

Harrigan et al. compared the in vitro effects of prodrug concentration on the potency of ACE inhibitor metabolites $^{52}$. The results prompted the investigators to speculate that interactions between the ester prodrug and diacid metabolites may be the basis of differences in the hemodynamic effects of ACE inhibitors. It is possible that prodrugs, which themselves act as ACE inhibitors, may modify the activity of their active metabolites and therefore their hemodynamic effects, particularly after the first dose. Perindopril and perindoprilat exhibit equivalent affinity for ACE, so the replacement of perindopril with its metabolite at the receptor-binding site is progressive. Enalaprilat has a higher affinity for ACE than enalapril; hence, replacement by enalaprilat occurs more quickly, inducing a more rapid fall in BP.

Perindopril is a lipophilic drug with high oral bioavailability ${ }^{51,53}$. It is therefore likely to achieve sufficiently high tissue concentrations to compete with its active diacid metabolite, perindoprilat, for binding with ACE. Competition between perindopril and perindoprilat for binding of tissue ACE may underlie the progressive onset of action noted with administration of perindopril. This would explain the lack of a significant first-dose hypotensive effect with this drug. Similar fosinopril with high lipophilicity and active prodrug fosinoprilat produced less falling BP after first dose $\mathrm{B}^{31,50}$.

\section{CONCLUSIONS}

The propensity for ACE inhibitors to cause first-dose hypotension in some patients is well established. The main 
uses of ACE inhibitors are to reduce arterial hypertension, improve survival in chronic heart failure, and delay progression to heart failure in patients with left ventricular dysfunction (LVD) following myocardial infarction. In the last two indications, first-dose hypotension is unwelcome but should not prevent the vast majority of patients with LVD and / or chronic heart failure from obtaining the benefits of ACE inhibitor therapy.

It is possible to minimize the incidence or severity (or both) of first-dose hypotension. Initial dosages of an ACE inhibitor can be titrated, and at-risk patients can be identified so that therapy can be commenced in a controlled environment where appropriate. Moreover, there is increasing evidence of differences in the profiles of firstdose hypotension induced by individual ACE inhibitors. Well controlled clinical trials have demonstrated that the acute hypotensive effect of captopril occurs rapidly but is of short duration, whereas that of enalapril is delayed and longer lasting. Similarly, the hypotensive effect of quinapril is also prolonged. In contrast, perindopril or fosinopril produces a gradual, modest decrease in BP that is not significantly different from placebo.

The reasons for these differences are unknown, but it has been speculated that physicochemical variations in the interaction between prodrugs and active metabolites result in differences in tissue concentrations and local inhibition of ACE.

In summary, ACE inhibitors are not equivalent in terms of their first-dose hypotensive effect. Specific differences between these drugs may hold some practical importance importance for clinicians attempting to minimize or circumvent first-dose hypotension when commencing ACE inhibitor therapy.

\section{REFERENCES}

1. Pfeffer MA, Braunwald E, Moyé LA, Basta L, Braun EDzh, Kaddi TE, Devis BR, Geltman EM, Goldman S, Fleiker GS (on behalf of the SAVE investigators). (1992) Effect of captopril on mortality and morbidity in patients with LVD after myocardial infarction. Results of the Survival and Ventricular Enlargement Trial. N Engl J Med 327, 669-677.

2. Dickstein K.,Kjekshus J. and OPTIMAAL Study Group. (1992) Effects od losartan nad captopril on mortality and morbidity in high-risk patients after acute myocardial infarction:the OPTIMAAL randomised trial. Lancet 360, 752-760.

3. Mets TF. Drug-induced orthostatic hypotension in older patients.(1995) Drugs Aging 6, 219-228.

4. Lipsitz LA, Jonsson PV, Kelley MM, Koestner JS. (1991) Causes and correlates of recurrent falls in ambulatory frail elderly. J Gerontol. 46, M 114-122.

5. Robbins AS, Rubenstein LZ, Josephson KR, Schulman BL, Osterweil D, Fine G. (1989) Predictors of falls among elderly people: results of two-population-based studies. Arch Intern Med 149, 1628-1633.

6. Rutan GH, Hermanson B, Bild DE, Kittner SJ, LaBaw F, Tell GS. (1992) Orthostatic hypotension in older adults: the cardiovascular health study. Hypertension 19, 508-519.

7. Belmin J, Lévy BI, Michel JB. (1994) Changes in the renin-angiotensin-aldosterone axis in later life. Drugs Aging 5, 391-400.

8. Cleland JGF, Dargie HJ, McAlpine H, Ball SG, Morton JJ, Robertson JI, Ford I. (1985) Severe hypotension after first dose of enalapril in heart failure. Br Med J 291, 1309-1312.
9. Cleland JGF. (1985) ACE inhibitors and heart failure Lancet 339, 687.

10. Packer M, Kessler P, Gottlieb SS. (1985) Adverse effects of converting enzyme inhibition in patients with severe congestive heart failure: pathophysiology and management. Postgrad Med J 62 Suppl $1,179-182$.

11. Mets TF, De Bock V, Praet JP. (1992) First-dose hypotension, ACE inhibitors and heart failure in the elderly. Lancet 339, 1487.

12. Campbell AJ. (1991) Drug treatment as a cause of falls on old age. A review of offending agents. Drugs Aging 1, 289-302.

13. Braunwald E. (1991) ACE inhibitors: a cornerstone of the treatment of heart failure. N. Engl. J. Med 325, 351-353.

14. SOLVD (Studies of Left Ventricular Dysfunction) Investigators. (1991) Effect of enalapril on survival in patients with reduced left ventricular ejection fractions and congestive heart failure. N Engl J Med 325, 294-302.

15. CONSENSUS Trial Study Group. (1987) Effects of enalapril on mortality in severe congestive heart failure. Resuslt of the Cooperative North Scandinavian Enalapril Survival Study (CONSENSUS). N Engl J Med 316, 1429-1435.

16. Acute infarction Ramipiril Efficacy (AIRE) Study Investigators. (1993) Effect of ramipril on mortality and morbidity of survivors of acute myocardial infarction with clinical evidence of heart failure. Lancet 342, 821-828.

17. Cohn JN, Johnson G, Ziesche S, Cobb F, Francis G, Tristani F, Smith R, Dunkman WB, Loeb H, Wong M. (1991) A comparison of enalapril with hydralazine isosorbide dinitrate in the treatment of chronic congestive heart failure. N Engl J Med 325, 303-310.

18. Chinese Cardiac Study Collaborative Group. (1995) Oral captopril versus placebo among 13634 patients with suspected acute myocardial infarction: interim report from the Chinese Cardiac Study (CCS-1). Lancet 345, 686-687.

19. Reid J, Lees KR, Squire L. (1995) First Dose Hypotension and ACE Inhibitors in Heart Failure. Clinical Relevance and Implications. Adis International 1-26.

20. Remme WJ. (2001) Hypotension After First-Dose ACE Inhibitor Administration in Heart failure - Should Doctors Stop Worrying? Cardiovasc. Drug Ther 15, 475-477.

21. Captopril Multicenter Research Group. (1983) A placebo-controlled trial of captopril in refractory chronic congestive heart failure. J Am Coll Cardiol 2, 755-763.

22. Di Carlo L, Chatterjee K, Parmley WW. (1983) Enalapril: a new angiotensin-converting enzyme inhibitor in chronic heart failure: Acute and chronic hemodynamic evaluations. J Am Coll Cardiol 2, 865-871.

23. Hasford J, Bussmann WD, Delius W, Koepcke W, Lehmann K, Weber E. (1991) First dose hypotension with enalapril and prazosin in congestive heart failure. Int J Cardiol 31, 287-294.

24. Packer M, Lee WH, Yushak M, Medina N. (1986) Comparison of captopril and enalapril in patients with severe chronic heart failure. N Engl Med 315, 847-853.

25. Dickstein K, Aarsland T, Tjelta K, Cirillo VJ, Gomez HJ. (1987) A comparison of hypotensive response after oral and intravenous administration of enalapril and lisinopril in chronic heart failure. J Cardiol Pharmacol 9, 705-710.

26. Otterstadt JE, Froeland G. (1992) First-dose blood pressure response in mild-to-moderate heart failure: a randomized doubleblind study comparing enalapril with lisinopril by 24 hour noninvasive blood pressure monitoring. Am. J. Cardiol. 70, 132-134.

27. Kamlow F, Cruickshank JM, Neil-Dewyer G, Dorrance DE, Hayes Y, Patel S, Wainwright RJ. (1990) First-dose effects of enalapril and atenolol upon blood pressure and cerebral blood flow in patients with mild to moderate hypertension on diuretic therapy. J Hum Hypertens 4, 528-525.

28. Squire IB, MacFadyen RJ, Lees KR, Hillis WS, Reid JL. (1994) Haemodynamic response and pharmacokinetics after the first dose of quinapril in patients with congestive heart failure. Br J Clin Pharmacol 38, 117-123.

29. Vítovec J, Špinar J, Czech and Slovak Investigator Group. (2000) First-dose hypotension after angiotensin-converting enzyme (ACE) inhibitors in chronic heart failure: a comparison of enalapril and perindopril. Europ. J Heart Failure 2, 299-304. 
30. Spinarova L, Spinar J, Vítovec J. (1994) Changes in blood pressure and heart rate during treatment with the ACE inhibitor spirapril - comparison of the first dose and chronic use. Cor Vasa 36, 73-76.

31. Eryonucu B, Koldas L, Ayan F, Keser N, Sirmaci A. (2001) Comparison of the First Dose response of Fosinopril and Captopril in Congestive Heart failure. Jpn Heart J 42, 185-191.

32. ISIS-4 (Fourth International Study of Infarct Survival) Collaborative Group. (1995) ISIS-4: a randomised factorial trial assessing early oral captopril, oral mononitrate, and intravenous magnesium sulphate in 58050 patients with suspected acute myocardial infarction. Lancet 345, 669-685.

33. Navookarasu NT, Rahman ARA, Abdullah I. (1999) First-dose response to angiotensin-converting enzyme inhibition in congestive cardiac failure: A Malaysian Experience. Int J Clin Pract 53, 25-30.

34. Jansen PAF, De Vries OOJ, De Rooy SEJA, Raymakers JA. (2001) Blood pressure reduction after the first dose captopril and perindopril. J Am Geriatr Soc 49, 1574-1575.

35. Bagger JP. (1997) Adverse event with first-dose perindopril in congestive heart failure. Lancet 350, 1671-1672.

36. Gruppo Italiano per lo Studio della Sopravvivenza nell'Infarcto miocardico. (1994) GISSI-3: effects of lisinopril and transdermal glyceryl trinitrate singly and together on 6week mortality and ventricular function after acute myocardial infarction. Lancet 340 , $1115-1122$.

37. Kober L, Torp-Pedersen C, Carlsen JE, Bagger H, Eliasen P, Lyngborg K, Videbaek J, Cole DS, Auclert L, Pauly NC. (1995) A clinical trial of the ACE inhibitor trandolapril in patients with left ventricular dysfunction after myocardial infarction (TRACE) N Engl J Med 333, 1670-1676.

38. Swedberg K, Held P, Kjekshus J., Rasmussen K, Ryden L, Wedel H. (1992) Effects of the early administration of enalapril on mortality in patients with acute myocardial infarction. Results of the Cooperative New Scandinavian Enalapril Survival Study II (CONSENSUS II). N Engl J Med 327, 678-684.

39. McLay JS, McMurray J, Bridges A, Struthers AD. (1992) Practical issues when initiating captopril therapy in chronic heart failure. What is the appropriate dose and how long should patients be observed? Europ Heart J 13, 1521-1527.

40. Spinar J, Vitovec J, Pluhacek L., Spinarova L, Fischerova B, Toman J. (2000) First dose hypotension after angiotensin converting enzyme inhibitor captopril and angiotensin II blocker losartan in patients with acute myocardial infarction. Int J Cardiol 75, 197-204.

41. Berkin KE, Ball SG. (2000) First dose hypotension after infarction. Int J Cardiol 76, 5-6.

42. Pfeffer MA, McMurray JJV, Velazquez EJ, Rouleau JL, Kober L, Maggioni AP, Solomon SD, Swedberg K, Van de Werf F, White H, Leimberger JD, Henis M, Edwards S, Zelenkofske S, Sellers MA, Califf RM; Valsartan in Acute Myocardial Infarction Trial Investigators. (for VALIANT Investigators) (2003) Valsartan, Captopril, or Both in Myocardial Infarction Complicated by Heart Failure, Left Ventricular Dysfunction, or Both. N Engl J Med 349, 1893-1906.

43. The HOPE investigators. (2000) Effects of angiotensin-convertingenzyme inhibitor ramipril, on cardiovascular events in high-risk patients. N Eng J Med 342, 145-153.

44. The EURopean trial On reduction of cardiac events with Perindopril in stable coronary Artery disease Investigators. (2003) Efficacy of perindopril in reduction of cardiovascular events among patients with stable coronary artery disease: randomised, double-blind, placebo-contolled, multicentre trial (the EUROPA study). Lancet 362, 782-788.
45. Lang RM, DiBianco R, Broderick GT, Gottlieb SS, Kostis J, Lyle PA, Makris L, Rajfer SI, Rucinska EJ. (1994) First-dose effects of enalapril $2.5 \mathrm{mg}$ and captopril 6.25 in patients with heart failure: a double-blind, randomized, multicenter study. Am Heart J 128, 551-556.

46. MacFadyen RJ, Lees KR, Reid JL. (1991) Differences in first dose response to angiotensin converting enzyme inhibition in congestive heart failure: a placebo controlled study. Br Heart J 66, 206-211.

47. Hood Jr WB, Youngblood M, Ghali JK, Reid M, Rogers WJ, Howe D, Teo KK, LeJemtel TH. (1991) Initial blood pressure response to enalapril in hospitalised patients (Studies on Left Ventricular Dysfunction (SOLVD). Am J Cardiol 68, 1465-1468.

48. Motwani JG, Fenwick MK, Morton JJ, Struthers AD. (1994) Determinants of the initial effects of captopril on blood pressure, glomerular filtration rate, and natriuresis in mild-to-moderate chronic congestive heart failure secondary to coronary artery disease. Am J Cardiol 73, 1191-1196.

49. Capewell S, Capewell A. (1991) "First dose" hypotension and venodilatation. Br J Clin Pharmacol 31, 213-215.

50. Thind GS. (1990) Angiotensin converting enzyme inhibitors: comparative structure, pharmacokinetics, and pharmacodynamics. Cardiovasc. Drugs Ther 4, 199-206.

51. MacFadyen RJ, Lees KR, Reid JL. (1991) Blood Pressure responses to low-dose oral ester or intravenous diacid angiotensin converting enzyme inhibitors. J Hypertens 9 (Suppl. 6), 376-377.

52. Harrigan JR, Hughes DM, Meredith PA. (1989) Charakterisation of the effects of prodrug concentration on the in vitro potency of the metabolites of five ACE inhibitors (abstract). Eur J Clin Pharm 36 (Suppl.), A186

53. Todd PA, Fitton A. (1991) Perindopril. A review of its pharmacological properties and therapeutic use in cardiovascular disorders. Drugs 42, 90-114.

54. Portuguese Community Hospital Study Group on Heart Failure. (2001) A Comparative Study of the First Dose Hypotensive Effects of Captopril and Perindopril in Patients with Heart Failure. Cardiovasc. Drug Ther 15, 501-506.

55. Mark AL. (1983) The Bezold-Jarisch reflex revisited. Clinical implications of inhibitory reflexes originating in the heart. J Am Coll Cardiol 1, 90-102.

56. Thanikachalam S, Manchanda SC. (2003) Incidence and Risk Factors of Asymptomatic First-Dose Hypotension With AngiotensinConverting Enzyme Inhibitors in Chronic Heart Failure due to Systolic Dysfunction. Indian. Heart J. 55, 167-171.

57. Squier IB., MacFadyen RJ., Reid JL. (1996) Differing Early Blood Pressure and Renin-Angiotensin System Responses to the First Dose of Angiotensin-Converting Enzyme Inhibitors in Congestive Heart Failure. J Cardiovasc Pharmacol 27, 657-666.

58. Hricik DE. (1985) Captopril-induced renal insufficiency and the role of sodium balance. Ann Intern Med 103, 222-223.

59. Semple PF, Thoren P, Lever AF. (1988) Vasovagal reactions to cardiovascular drugs: the first dose effect. J Hypertens 6, 601-606.

60. Mc Murray J, Matthews DM. (1985) Effect of diarrhoea on a patient taking captopril. Lancet 1,581 .

61. Weber S, Vaur L, Ounnoughene Z, Schwob J, Dubroca I, Normand J, Etienne S, Charbonnier B. (2002) Acute blood pressure response to trandolapril and captopril in patients with left ventricular dysfunction after acute myocardial infarction. Am Heart J 143, 313-318.

62. Cohn JN, Tognoni G., for the Valsartan Heart Failure Trial Investigators. (2001) A randomized trial of the angiotensin-receptor blocker valsartan in chronic heart failure. New Engl J Med 345, 1667-1675. 